\title{
sciendo
}

\section{EFFECTS OF DIETARY OXIDIZED OIL ON GROWTH PERFORMANCE, MEAT QUALITY AND BIOCHEMICAL INDICES IN POULTRY -}

\section{A REVIEW}

\author{
Shafqat Nawaz Qaisrani ${ }^{1 \bullet}$, Muhammad Rizwan ${ }^{1}$, Ghulam Yaseen ${ }^{1}$, Fehmeeda Bibi ${ }^{2}$, \\ Muhammad Awais Sarfraz ${ }^{1}$, Nazir Ahmed Khan ${ }^{3}$, Saima Naveed ${ }^{1}$, Talat Naseer Pasha ${ }^{1,2}$ \\ ${ }^{1}$ Department of Animal Nutrition, University of Veterinary and Animal Sciences, Lahore 54000, \\ Pakistan \\ ${ }^{2}$ Department of Zoology, University of Education Lahore, Multan Campus 66000, Pakistan \\ ${ }^{3}$ Department of Animal Nutrition, Faculty of Animal Husbandry and Veterinary Sciences, \\ The University of Agriculture Peshawar, Peshawar, Pakistan \\ •Corresponding author: shafqat.qaisrani@uvas.edu.pk
}

\begin{abstract}
Lipids (fats and oils) are a concentrated source of energy in poultry diets that improves palatability, feed consistency, provides essential fatty acids and increases the absorption of fat-soluble vitamins. Fresh oil is an expensive energy source and its exposure to air, heat, metallic catalyst during storage and processing may lead to its oxidative deterioration. This review highlights the response of modern poultry to dietary oxidized oil on growth performance, nutrients digestibility, gut health, carcass characteristics, meat quality, blood chemistry and tissue oxidative status. Literature shows that in moderately (peroxide value (PV): 20 to $50 \mathrm{meq} \mathrm{kg}^{-1}$ ) and highly (PV: 50 to 100 meq $\mathrm{kg}^{-1}$ or above) oxidized oils, lipid peroxidation causes rancid odours and flavours that negatively affect feed palatability, reduces intestinal villus height that decreases the surface area available for nutrients absorption. The oxidation products also damage fat soluble vitamins (A, D, $\mathbf{E}$ and $\mathrm{K}$ ) in blood resulting in an oxidative stress. The use of oxidized oil in poultry diets has no significant effect on dressing percentage, $\mathrm{pH}$ and meat colour, whereas carcass weight decreases and drip loss of meat increases. Overall, there is a contradictory data regarding the influence of oxidized oil in poultry feed depending on the PV and inclusion levels. The reviewed literature shows that the use of mildly oxidized $\left(\mathrm{PV}<20 \mathrm{meq} \mathrm{kg}^{-1}\right)$ oil in poultry feed with 4 to $5 \%$ inclusion level decreases the feed cost and ultimately cost of poultry production without compromising their growth performance. It can, therefore, partially replace fresh oil as an efficient, cost effective and sustainable energy source in poultry diets.
\end{abstract}

Key words: oxidized oil, growth performance, meat quality, poultry

Carbohydrates and lipids (fats and oils) are the main energy sources in poultry ration. Lipids provide about 2.25 times greater energy compared with carbohydrates 
and proteins, and are obtained from both vegetable and animal sources. The building blocks of lipids are fatty acids that form bonds with various compounds to make corresponding lipids. These fatty acids are further categorized based on their chain length, number and configuration of double bonds. Fatty acids, because of the presence of double bond, are divided into saturated (without double bond), unsaturated (with double bond), monounsaturated (with one double bond) and polyunsaturated fatty acids (PUFAs) (with two or more double bonds) (Orsavova et al., 2015). Vegetable oils, rich in PUFAs, are used in broiler ration to enhance their growth performance because of their high digestibility (Engberg et al., 1996). Fats with longer chain length and a higher degree of saturation result in a lower fat absorption leading to a lower nitrogen corrected apparent metabolizable energy. Fats with greater proportion of short- and mid-chain fatty acids (C4:0-C14:0) are well absorbed compared to long-chain animal fats (Ketels and De Groote, 1988). Inclusion of oil in poultry diets helps birds to overcome growth depression and manage heat stress (Gous and Morris, 2005; Wang et al., 2016). Lipids increase the energy content of the diet, decrease feed dustiness (Varady et al., 2012), enhance feed palatability (Cleland et al., 2005), consistency and fat soluble vitamins absorption, and supply of essential fatty acids leading to an improved zootechnical performance of the birds (Braga and Baiao, 2001; Junqueira et al., 2005).

\section{Lipid oxidation}

Lipid oxidation is a procedure where oxidants including free radicals or non-radical species invade lipids having carbon-carbon double bond(s) that involve hydrogen abstraction from a carbon with oxygen insertion, particularly in PUFAs, leading to production of hydroperoxides and lipid peroxyl radicals (Yin et al., 2011). The process of lipid oxidation is divided into three phases including initiation, propagation and termination with each phase consuming and producing primary, secondary and tertiary complexes, respectively (Belitz et al., 2009). Lipid oxidation consists of a chain reaction that yields and utilizes substances including peroxides, aldehydes and polar compounds by weakening the oil antioxidant capability. The level of oxidation varies and depends upon oil composition, temperature and extent of thermal processing. Since there is no single measure to evaluate the oxidation status of oil, it is biologically more descriptive to test different markers of oxidation. (Lindblom et al., 2019). Many peroxidation compounds including acids, aldehydes, and polymerized fatty acids formed during lipid peroxidation process can be assessed to evaluate the severity of lipid peroxidation (Kerr et al., 2015). The peroxide value (PV) measures primary products including lipid peroxides and hydroperoxides contents that are produced in the initiation phase. The PV is expressed as milliequivalents per kilogram (meq $\mathrm{kg}^{-1}$ ) and tends to be highest in the initiation phase and decreases in the propagation and termination phases (Shurson et al., 2015). The propagation phase produces secondary oxidation products including aldehydes, ketones and acids which are commonly estimated by thiobarbituric acid reactive substances and p-anisidine value. P-anisidine value measures the total molecular weight of saturated and unsaturated aldehydes. Thiobarbituric acid reactive substances are indirect measure of malondialdehyde, formed in lipid peroxidation, whereas there are other aldehydes 
contributing to the thiobarbituric acid reactive substances value not specific to lipid peroxidation (Kerr et al., 2015). The termination phase follows the propagation phase and is supposed to yield the most harmful products of lipid peroxidation relative to DNA, protein or lipid damage.

Lipid peroxidation, in high PUFA oils, during storage and processing may lead to deterioration of unsaturated fatty acids resulting in a reduced digestibility of energy in broilers (Engberg et al., 1996; Wiseman, 1999). Oxidized fats also cause destruction of pigments, amino acids and fat soluble vitamins (A, D, E and K) (Zdunczyk et al., 2002). The oxidation of lipids is a serious issue for food industry and consumers since it decreases the shelf life of meat and meat products resulting in increased rancid odours and bad flavours in it (Lima et al., 2013). The production of free radicals during oxidation process can be a potential threat for consumer health as well (Jakobsen, 1999). The consumption of such oxidative compounds can increase nutrients damage, particularly those of unsaturated fatty acids and vitamin E, leading to an increased oxidative stress that is linked with muscle dystrophy, exudative diathesis, encephalomalacia, tissue necrosis of different organs and lower rates of fertility and hatchability (Cabel et al., 1988).

Global frying of food in heated oil/fat is a popular method of food preparation to develop desirable flavour, aroma, golden brown and crispy texture. The repeated heating, however, of oils and fats at deep frying temperature $\left(150\right.$ to $\left.190^{\circ} \mathrm{C}\right)$, particularly for extended period, predisposes the unsaturated fatty acids to thermal oxidation and polymerization leading to a partial transformation of unsaturated fatty acids into saturated and trans-fatty acid. As a result of oxidation, free radicals, peroxides and secondary oxidation products including ketones and aldehydes are formed (Frankel, 1991). Oils retrieved from frying industry can be a convenient energy source for animal feed (Tres et al., 2013). Provision of feed, containing oxidized oil, to broilers and turkeys resulted in a decreased growth performance and feed efficiency (Engberg et al., 1996; Jankowski et al., 2000) possibly due to a decreased feed intake because of off flavour, reduced palatability and digestibility of the feed. Oxidized fat in diets has a significant effect on the production of lipid rancidity in meat products that leads to an increased drip loss and a decrease in its shelf life (Jensen et al., 1997; Delles et al., 2015).

The contribution of oxidized fats to overall energy consumption has been distinctly expanded in developed countries mainly because of increased fast food consumption comprised of heated and processed dietary fats, including frying oil. The current review highlights the response of modern poultry to supplementation of oxidized oil on growth performance, nutrients digestibility, gut health, carcass characteristics, meat quality, blood chemistry and tissue oxidative status.

\section{Influence of dietary oxidized oil in poultry}

\section{Effects on growth performance}

Growth performance is measured in terms of feed intake (FI), body weight gain (BWG) and feed conversion ratio (FCR) and, in general, reflects the nutritional quality of the diet. Development of rancid odour and off flavour due to secondary oxidation products including aldehydes can influence palatability and feed intake in 
poultry (Dibner et al., 1996). These oxidation products reduced fat retention to $1.4 \%$ and energy value of the diet by $1 \%$, resulting in a lower BWG in broilers (Engberg et al., 1996). Tavarez et al. (2011) performed a study to examine the influence of oil quality (PV: 180 meq kg-1 of oil) and antioxidant inclusion (blend of ethoxyquin and propyl gallate at two levels; 0 or $135 \mathrm{mg} / \mathrm{kg}$ ) in broilers and observed that antioxidant supplemented diets increased FI by $2.4 \%$ and BWG by $4 \%$, whereas FCR remained unaffected compared to the birds in control group (PV: $1 \mathrm{meq} \mathrm{kg}^{-1}$ ).

Zhang et al. (2011) executed a trial to examine the effects of oxidized oil with and without supplementation of antioxidant on growth performance in broilers during 4 to 6 weeks of age and found no significant effects in broilers fed control diet ( $5 \%$ fresh vegetable or animal fat), diet with oxidized fats $(5 \%$ fresh vegetable or animal fat, PV: 100 meq $\mathrm{kg}^{-1}$ ) and diet containing oxidized fat supplemented with antioxidants (5\% fresh vegetable or animal fat, $200 \mathrm{ppm}$ BHA, $500 \mathrm{IU}$ vitamin E). Tan et al. (2018 a), similarly, offered diets containing 4\% fresh (PV: $20 \mathrm{meq} \mathrm{kg}^{-1}$ ), mildly oxidized (PV: 140 meq kg-1), moderately oxidized (PV: $183 \mathrm{meq} \mathrm{kg}^{-1}$ ) and highly oxidized (PV: $277 \mathrm{meq} \mathrm{kg}^{-1}$ ) fish oil to broilers during 1 to 21 days to evaluate their effects on growth performance. In contrast to the previous study, these authors reported that broilers fed oxidized fish oil reduced body weight by $7.25 \%$, increased FI by $2.10 \%$ and FCR by $10.4 \%$ compared to those fed fresh fish oil based diets. Bayraktar et al. (2011) did not find any significant difference in FI and BWG in heat stressed male broilers fed diets containing oxidized oil (PV: $100 \mathrm{meq} \mathrm{kg}{ }^{-1}$ ), oxidized diet with $\alpha$-tocopherol acetate (vitamin E, $75 \mathrm{mg} \mathrm{kg}^{-1}$ ) and control group with fresh sunflower oil and $\alpha$-tocopherol acetate $\left(75 \mathrm{mg} \mathrm{kg}^{-1}\right)$ during 4 to 6 weeks of the age. Studies in rats reported that FI and BWG were not affected by oxidized oil (PV: 150 meq $\left.\mathrm{kg}^{-1}\right)$ containing vitamin $\mathrm{E}\left(250 \mathrm{mg} \mathrm{kg}^{-1}\right)$ in comparison with those fed control diet containing fresh fat (PV: 1.6 meq $\mathrm{kg}^{-1}$ ) with vitamin $\mathrm{E}\left(250 \mathrm{mg} \mathrm{kg}^{-1}\right)$ (Eder et al., 2002; Keller et al., 2004). Acikgoz et al. (2011) compared the influence of feeding dietary oxidized oil (PV: 148 meq $\mathrm{kg}^{-1}$ ) with or without vitamin E supplementation with fresh oil (PV: 1 meq $\mathrm{kg}^{-1}$ ) based diets and observed no significant difference in growth performance of broilers. Zdunczyk et al. (2000), similarly, used mildly (PV: 5 meq $\mathrm{kg}^{-1}$ ) oxidized oil in the diets of rats and reported that feed palatability, protein and fat digestibility remained unaffected, consequently FCR and body weight gain. Some studies, in contrast, reported that oxidized oil in turkeys and rats impaired their health and growth (Jankowski et al., 2000; Zdunczyk et al., 2002; Eder et al., 2003). Detrimental effects of oxidized oil in these studies were possibly due to the use of oils with high PV (100-150 meq $\mathrm{kg}^{-1}$ ) or higher secondary oxidation products of lipids. Tan et al. (2018 b) offered broilers diets containing 4\% fresh (PV: $3.7 \mathrm{meq} \mathrm{kg}^{-1}$ ), low oxidized (PV: 25 meq kg-1), moderately oxidized (PV: 56 meq kg-1) or highly oxidized (PV: 73 meq $\mathrm{kg}^{-1}$ ) soybean oil from 0 to 21 days of age to evaluate the growth performance. The broilers fed highly oxidized oil based diets resulted in an increased FI by $7.3 \%$ and BWG by 3.6\% compared to those fed fresh oil based diets.

Da Rocha et al. (2012) executed a trial to examine the effects of different levels of oxidized fat (PV: 0, 110, $250 \mathrm{meq} \mathrm{kg}^{-1}$ ) and supplementation of vitamin E (65 or $800 \mathrm{mg} \mathrm{kg}^{-1}$ of diets) on growth performance of turkeys and found no difference in FCR by the oxidation levels. Engberg et al. (1996) reported that broilers fed diets 
containing 11\% fresh (PV: 1 meq $\mathrm{kg}^{-1}$ ) vegetable oil and oxidized oil (PV: 156 meq $\mathrm{kg}^{-1}$ ) did not show any significant effect on FI and FCR. Jankowski et al. (2000) studied the effects of $2 \%$ dietary fat with different PV $\left(<5,50,100\right.$ and $\left.150 \mathrm{meq} \mathrm{kg}^{-1}\right)$ on growth performance in turkeys and reported that BWG remained unaffected at 4 and 8 weeks of age irrespective of the dietary treatments. Turkeys fed diets containing higher level of fat peroxides (PV: 150 meq $\mathrm{kg}^{-1}$ ) showed 10\% less FI and $11.4 \%$ lower BWG compared with the birds that fed diets with a lower fat PV $(<5$ meq kg-1) at 12 and 16 weeks of age. Zdunczyk et al. (2002) performed a study to examine the growth performance of turkeys by supplementing fat with varied degrees of oxidation (PV: $<5,50,100,150$ meq kg-1) and concluded that oxidized fat led to a $1.64 \%$ decrease in BWG of turkeys because of decreased $(8.5 \%)$ feed intake. Lin et al. (1989) investigated the effects of fresh (PV: $1 \mathrm{meq} \mathrm{kg}^{-1}$ ) and oxidized (PV: 400 meq $\mathrm{kg}^{-1}$ ) sunflower oil based diets on growth performance of broilers and reported $4.2 \%$ lower BWG in broilers fed oxidized oil based diets compared with control (fresh oil). The decrease in growth rate by using oxidized sunflower oil may be due to low nutritional value and toxic effects of lipid oxidation products. Anjum et al. (2004) performed a study to examine the influence of feeding fresh (PV: $3 \mathrm{meq} \mathrm{kg}^{-1}$ ) vs. oxidized (PV: 50 meq $\mathrm{kg}^{-1}$ ) soybean oil on growth performance of broilers during 0 to 42 days of age and observed a 1.8\% decrease in FI and a $4.5 \%$ decrease in BWG in broilers consuming oxidized oil based diets than those fed fresh oil based diets. The influence of oxidized oil on growth performance in broilers is presented in Table 1.

Table 1. Effects of oxidized oil on growth performance ${ }^{1}$ in poultry

\begin{tabular}{|c|c|c|c|c|c|c|c|}
\hline \multirow{2}{*}{$\begin{array}{c}\text { Inclusion } \\
\text { level } \\
(\%)\end{array}$} & \multirow{2}{*}{$\begin{array}{l}\text { Oxidation level } \\
\left(\text { meq } \mathrm{kg}^{-1}\right)\end{array}$} & \multirow{2}{*}{$\begin{array}{l}\operatorname{Optimum}^{*} \\
\left(\mathrm{meq} \mathrm{kg}^{-1}\right)\end{array}$} & \multirow{2}{*}{ Days } & \multicolumn{3}{|c|}{ Growth performance $(\%)^{2}$} & \multirow{2}{*}{ References } \\
\hline & & & & FI & BWG & FCR & \\
\hline 4 & $20^{\mathrm{c}}, 140,183,277$ & 277 & $0-21$ & +2.09 & -7.25 & $\grave{\dagger}+10.44$ & Tan et al. $(2018 a)^{3}$ \\
\hline 4 & $3^{\mathrm{c}}, 25,56,73$ & 73 & $0-21$ & +7.34 & +3.62 & +3.05 & Tan et al. $(2018 b)^{3}$ \\
\hline 2 & $7.5^{\mathrm{c}}, 50.5,157,448.5$ & 448.5 & $0-21$ & +1.91 & -2.19 & +4.81 & Liang et al. $(2015)^{3}$ \\
\hline 3.5 & $0^{c}, 110,250$ & 250 & $0-22$ & +3.07 & +3.27 & -0.13 & Da Rocha et al. $(2012)^{4}$ \\
\hline 6 & $1^{\mathrm{c}}, 148$ & 148 & $21-42$ & +0.63 & -0.12 & +1.70 & Acikgoz et al. $(2011)^{3}$ \\
\hline 6 & $1^{\mathrm{c}}, 100$ & 100 & $28-42$ & +1.04 & +0.19 & -1.80 & Bayraktar et al. $(2011)^{3}$ \\
\hline 4 & $1^{\mathrm{c}}, 180$ & 180 & $0-39$ & -1.64 & -6.05 & +4.42 & Tavarez et al. $(2011)^{3}$ \\
\hline 5 & $1^{\mathrm{c}}, 100$ & 100 & $28-42$ & +1.34 & -0.72 & +2.31 & Zhang et al. $(2011)^{3}$ \\
\hline 2 & $3^{\mathrm{c}}, 50$ & 50 & $0-42$ & -1.75 & -4.47 & +2.99 & Anjum et al. $(2004)^{3}$ \\
\hline 2 & $5^{\mathrm{c}}, 50,100,150$ & 150 & $0-28$ & -8.58 & -1.64 & +2.10 & Zdunczyk et al. $(2002)^{4}$ \\
\hline 11 & $1^{\mathrm{c}}, 156$ & 156 & $0-28$ & -7.20 & -7.80 & +0.68 & Engberg et al. (1996) ${ }^{3}$ \\
\hline 5.5 & $1^{\mathrm{c}}, 400$ & 400 & $28-49$ & -1.81 & -4.21 & +2.94 & Lin et al. $(1989)^{3}$ \\
\hline
\end{tabular}

${ }^{\mathrm{c}}$ Control.

*Highest oxidation level.

${ }^{1} \mathrm{FI}=$ Feed intake; $\mathrm{BWG}=$ Body weight gain $; \mathrm{FCR}=$ Feed conversion ratio.

${ }^{2} \pm$ These values indicate the difference between control and optimum level in \% age.

$+\mathrm{FCR}=$ Poor feed conversion ratio.

FCR $=$ Improved feed conversion ratio.

${ }^{3}$ Studied in broiler.

${ }^{4}$ Studied in turkey. 
This literature review suggests that supplementation of oxidized oil (PV: 25 to 448.5 meq $\mathrm{kg}^{-1}$ ) with the inclusion of 2 to $11 \%$ in poultry (broilers and turkeys) diets for a period of 0 to 49 days, resulted in 1 to $8 \%$ decrease in FI, 0.5 to $8 \%$ reduction in BWG and 2 to $10 \%$ poorer FCR.

Effects on nutrients digestibility

Acikgoz et al. (2011) investigated the nutrients digestibility in broilers by supplementing the oxidized (PV: $148 \mathrm{meq} \mathrm{kg}^{-1}$ ) oil with or without vitamin $\mathrm{E}$ and did not observe any significant effect on digestibility coefficients of crude protein and fat in male broilers during the grower phase (22-42 days). The apparent crude-fat digestibility was, however, decreased from 95\% (fresh fish oil) to 91\% (PV: $200 \mathrm{meq} \mathrm{kg}^{-1}$ ) and 74\% (PV: 400 meq kg-1) in mink (Borsting et al., 1994). Engberg et al. (1996) executed a study to examine the digestibility response of broilers fed oxidized oil based diets (PV: $156 \mathrm{meq} \mathrm{kg}^{-1}$ ) and reported no significant difference in the retention of DM and nitrogen, whereas about $1.6 \%$ reduction in energy and fat retention was observed compared with the birds fed fresh oil based diets.

\section{Effects on gut health}

Gastrointestinal tract is an organ system that mediates uptake of nutrients. Healthy gut is, therefore, the foundation for optimum performance of the birds. Gut health includes effective digestion and absorption of nutrients and operative immune response. Intestinal villi is a basic site for the nutrients absorption and its surface area mainly controls absorption efficiency of nutrients. High digestive and absorptive functions of the intestine is directly related to increased villus height and surface area of intestine (Amat et al., 1996). Da Rocha et al. (2012) conducted a study on turkeys to evaluate gut health in response to feeding of oxidized soybean oil (PV: 250 meq $\mathrm{kg}^{-1}$ ). The study showed that birds fed diets containing oxidized soybean oil had $14 \%$ decrease in villus height, which the authors related to the effects of primary and secondary oxidation products on intestinal epithelium. Some of the oxidation products including aldehydes, acids, ketones and esters were assumed to have deleterious effects that led to destruction of the brush border membrane (Kimura et al., 1984). According to Yamauchi and Isshiki (1991) when an agent that disturbs the balance in cell loss and regeneration comes in contact with the intestine a decrease in villus height is observed as a response of intestine to that particular agent. Dibner et al. (1996) conducted a trial on broilers by providing diets with oxidized poultry fat (PV: 212.5 meq $\mathrm{kg}^{-1}$ ) and lard (pig fat) (PV: $3.2 \mathrm{meq} \mathrm{kg}^{-1}$ ) without supplementing any antioxidant to evaluate the gut health of birds and observed an increased cell turnover in the intestine. According to Dibner and Richards (2004), an increased degree of functional cells proliferation of gastrointestinal tract and its decreased lifetime was found in birds fed oxidized oil based diets. Reduction in villus height decreased the surface area available for nutrients absorption, digestive enzyme secretions and ultimately led to a poor performance of the broilers (Dibner et al., 1996).

Tan et al. (2018 b) performed an experiment to examine the effects of oxidized soybean oil with different degrees of oxidation (PV: 3.7, 25, 56 and 73 meq kg$~^{-1}$ ) on intestinal barrier functions in broilers and reported that different dietary oxidized oil levels did not cause any significant effect on intestinal morphology of the jejunum and ileum. A better absorption of unsaturated fats than saturated fats in intestine led 
to an improved growth performance during starter phase of broilers. During the first week of age low utilization of fat was due to limited bile secretion and reduced activity of lipase (Mossab et al., 2000). The broilers fed oxidized oil based diets showed more proliferation in the gut and liver cells that enhanced the tissues maintenance requirements, ultimately leading to a poorer FCR (Dibner et al., 1996).

The above mentioned studies reported a small decrease in villus height of jejunum in birds (broilers and turkeys) fed diets containing oxidized oil. The decrease in height of villus was, however, non-significant compared to the birds fed fresh oil based diets.

\section{Effects on carcass characteristics and meat quality}

Effects of oxidized oil on concentrations of fat soluble vitamins in the liver and skeletal muscles are shown in Table 2, whereas effects of oxidized oil on carcass characteristics and meat quality of poultry are summarized in Table 3 . Heating of oil may lead to decreased capability of the broilers to metabolize and utilize energy as a result of increased primary, secondary and tertiary oxidation products that may enhance the oxidative stress in the birds (Ehr et al., 2015). Lin et al. (1989) concluded that the oxidative products destroy the fat-soluble vitamins (A, D, E and K) and reported $25 \%$ decreased concentration of $\alpha$-tocopherol in white and dark muscles of broilers fed diets supplemented with 5.5\% thermally oxidized (PV: 400 meq kg${ }^{-1}$ ) sunflower oil compared with birds fed fresh (PV: 1 meq kg-1) oil based diets. This reduced concentration of $\alpha$-tocopherol may be due to the damage of some $\alpha$-tocopherol contents in the diets by the dietary oxidized oil before offered to the broilers. A part of the $\alpha$-tocopherol present in tissue may protect the tissue lipids from oxidation. Engberg et al. (1996) examined the effects of oxidized oil (PV: $156 \mathrm{meq} \mathrm{kg}^{-1}$ ) based diets on tocopherol (vitamin E) levels and observed reduced concentrations of $\alpha$ and $\gamma$-tocopherol in all tissues of broilers. Zdunczyk et al. (2002) documented that inclusion of oxidized fat (PV: 150 meq $\mathrm{kg}^{-1}$ ) in turkey's diets caused $48.9 \%$ reduction in tocopherol concentration in hepatic cells. Jensen et al. (1997) performed an experiment to evaluate the effects of oxidized oil (PV: 156 meq kg-1) on meat quality and observed $41.7 \%$ reduction of $\alpha$-tocopherol level in breast muscles and $47.6 \%$ reduction in thigh muscles. The study also reported that the concentration of $\alpha$-tocopherol in muscles was $50 \%$ lower on a weight-to-weight basis in breast muscles compared to thigh muscles, regardless of the feeding regime.

Engberg et al. (1996) executed a study to find the effects of oxidized oil (PV: $156 \mathrm{meq} \mathrm{kg}^{-1}$ ) on the retinol (vitamin A) concentrations in broilers and indicated that birds fed oxidized oil based diets reduced retinol level by $13.7 \%$ in the liver and $21.8 \%$ in the abdominal fat compared with those fed fresh vegetable oil (PV: 1 meq $\mathrm{kg}^{-1}$ ) based diets. The observed difference of retinol in the tissues may potentially be due to its decreased availability in the intestine because of its destruction by oxidation products (aldehydes, acids, ketones and esters). Zdunczyk et al. (2002) performed an experiment to examine the influence of different oxidation levels (PV: $<5,50,100,150 \mathrm{meq} \mathrm{kg}^{-1}$ ) of oil on retinol concentration in turkeys and found $22.5 \%$ lower retinol level in the liver. Lu et al. (2014) reported that birds fed with $3 \%$ oxidized oil (PV: 180 meq kg-1) supplemented with vitamin $\mathrm{E}\left(10 \mathrm{IU} \mathrm{kg}^{-1}\right)$ in the diets caused a $17.4 \%$ decrease in the retinol concentration of breast muscles compared to 
control group (3\% non-oxidized oil + vitamin E at $10 \mathrm{IU} \mathrm{kg} \mathrm{kg}^{-1}$ ) with $1.3 \%$ increased drip loss.

Table 2. Concentrations of fat soluble vitamins in the liver and skeletal muscles of poultry fed diets containing oxidized oil

\begin{tabular}{|c|c|c|c|c|c|c|c|c|c|}
\hline \multirow{2}{*}{$\begin{array}{l}\text { Inclusion } \\
\text { level (\%) }\end{array}$} & \multirow{2}{*}{$\begin{array}{c}\text { Oxidation } \\
\text { level } \\
\left.(\text { meq kg })^{-1}\right)\end{array}$} & \multirow{2}{*}{$\begin{array}{l}\text { Optimum* } \\
(\text { meq kg }\end{array}$} & \multicolumn{3}{|c|}{$\begin{array}{l}\text { Retinol concentration } \\
(\%)^{1}\end{array}$} & \multicolumn{3}{|c|}{$\begin{array}{c}\text { Tocopherol } \\
\text { concentration }(\%)^{1}\end{array}$} & \multirow{2}{*}{ References } \\
\hline & & & liver & $\begin{array}{l}\text { breast } \\
\text { muscle }\end{array}$ & $\begin{array}{l}\text { thigh } \\
\text { muscle }\end{array}$ & liver & $\begin{array}{c}\text { breast } \\
\text { muscle }\end{array}$ & $\begin{array}{l}\text { thigh } \\
\text { muscle }\end{array}$ & \\
\hline 3 & $1^{\mathrm{c}}, 180$ & 180 & $\mathrm{ND}^{2}$ & -17.48 & ND & ND & -7.01 & ND & $\begin{array}{l}\text { Lu et al. } \\
(2014)^{3}\end{array}$ \\
\hline 4 & $1^{\mathrm{c}}, 180$ & 180 & -60.00 & ND & ND & -50.00 & ND & ND & $\begin{array}{l}\text { Tavarez et al. } \\
(2011)^{3}\end{array}$ \\
\hline 2 & $5^{\mathrm{c}}, 50,100,150$ & 150 & -22.52 & ND & ND & -48.98 & ND & ND & $\begin{array}{l}\text { Zdunczyk et } \\
\text { al. }(2002)^{4}\end{array}$ \\
\hline 2 & $5^{\mathrm{c}}, 50,100,150$ & 150 & -22.52 & ND & ND & -48.98 & ND & ND & $\begin{array}{l}\text { Jankowski et } \\
\text { al. }(2000)^{4}\end{array}$ \\
\hline 11 & $1^{c}, 156$ & 156 & ND & ND & ND & ND & $-41.69^{\dagger}$ & $-47.61^{\dagger}$ & $\begin{array}{l}\text { Jensen et al. } \\
(1997)^{3}\end{array}$ \\
\hline 11 & $1^{c}, 156$ & 156 & -13.77 & ND & -33.3 & $-48.41^{\dagger}$ & $-30.51^{\dagger}$ & -64.94 & $\begin{array}{l}\text { Engberg et al. } \\
(1996)^{3}\end{array}$ \\
\hline 8 & $1^{\mathrm{c}}, 55$ & 55 & ND & ND & ND & ND & $-80.8^{\dagger}$ & $-88.57^{\dagger}$ & $\begin{array}{l}\text { Sheehy et al. } \\
(1993)^{3}\end{array}$ \\
\hline
\end{tabular}

${ }^{\mathrm{c}} \mathrm{Control}$.

${ }^{*}$ Maximum oxidation level used.

${ }^{1} \pm$ These values indicate the difference between control and optimum level in $\%$ age.

${ }^{2}$ Not determined.

${ }^{\dagger} \alpha$-tocopherol.

${ }^{\dagger} \gamma$-tocopherol.

${ }^{3}$ Studied in broiler.

${ }^{4}$ Studied in turkey.

Carcass quality is measured by carcass weight, dressing percentage, breast yield, leg quarter yield and abdominal fat contents. Anjum et al. (2004) evaluated the response of carcass characteristics in broilers by feeding of oxidized (PV: $50 \mathrm{meq} \mathrm{kg}^{-1}$ ) and fresh (PV: 3 meq $\mathrm{kg}^{-1}$ ) soybean oil. The study reported no significant difference in dressing percentage and weights of internal organs (heart, gizzard and bursa) by supplementation of oxidized soybean oil, whereas liver weight was increased by $8 \%$ compared with the broilers fed fresh soybean oil based diets. Jankowski et al. (2000) evaluated the influence of varied degrees (PV: $<5,50,100,150 \mathrm{meq} \mathrm{kg}{ }^{-1}$ ) of oxidized oils on dressing percentage in turkeys and reported no significant difference in the carcass yield, breast and leg quarter yield. Lin et al. (1989), in contrast, reported that diets containing oxidized oil (PV: 400 meq $\mathrm{kg}^{-1}$ ) reduced the carcass weight of male broilers by $7.3 \%$ compared with birds fed fresh oil. Tavarez et al. (2011) conducted a study and, likewise, observed 5.1\% lower carcass weight with no effect on breast 
yield in broilers fed oxidized oil (PV: 180 meq $\mathrm{kg}^{-1}$ ) compared to those fed fresh oil (PV: 1 meq $\mathrm{kg}^{-1}$ ). In the mentioned study, however, dressing percentage remained unaffected in birds fed oxidized oil. Lu et al. (2014) performed a trial in broilers to compare the effects of feeding 3\% oxidized oil (PV: $180 \mathrm{meq} \mathrm{kg}^{-1}$ ) and vitamin E (10 IU kg $\mathrm{g}^{-1}$ ) supplementation. The study found no significant difference in carcass yields compared with the broilers fed with control diet (3\% non-oxidized oil + vitamin E at $10 \mathrm{IU} \mathrm{kg}^{-1}$ ). Supplementation of high PV fats in broiler diets did not influence percent yield of breast, fat pad, leg, thigh and wing (McGill et al., 2011). Inclusion of oxidized fat (PV: 150 meq kg-1) in turkey's diets did not influence carcass yield, breast and leg quarter yield and abdominal fat (Zdunczyk et al., 2002). Dietary oxidized poultry offal fat in broilers resulted in $0.18 \%$ and $0.22 \%$ increase in carcass weight and dressing percentage, whereas $1.16 \%$ and $1.46 \%$ decrease in breast and leg quarter yield compared with the group fed fresh poultry offal fat (Racanicci et al., 2008).

Meat quality is commonly described as a measurement of traits or characteristics that define the appropriateness of meat to be eaten as fresh or stored for reasonable time without any deterioration. Meat colour is a main quality attribute that is affected by age, sex, meat $\mathrm{pH}$, muscle pigmentations, pre-slaughtering and processing conditions (Sabow et al., 2016) and may also influence customers' acceptability of meat (Adeyemi et al., 2016). Feeding oxidized oil (PV: 100 meq $\mathrm{kg}^{-1}$ ) did not affect the colour of breast meat in broilers (Bayraktar et al., 2011). Lu et al. (2014) performed a trial to evaluate the meat colour by supplementing oxidized oil (PV: $180 \mathrm{meq} \mathrm{kg}^{-1}$ ) in broiler diets and documented that redness in the breast muscles was not affected. Tavarez et al. (2011) executed a study to examine the influence of oxidized oil (PV: $180 \mathrm{meq} \mathrm{kg}^{-1}$ ) on meat quality and reported that broilers fed diets containing oxidized oil showed $25.4 \%$ increase in yellowness compared with the birds fed fresh oil based diets. Zhang et al. (2011) investigated the influence of control (with 5\% fresh animal or vegetable fat), oxidized (with 5\% oxidized fat at PV: $100 \mathrm{meq} \mathrm{kg}^{-1}$ ) and antioxidants supplemented (with 5\% fresh fat, 500 IU vitamin E, and $200 \mathrm{ppm}$ butylated hydroxyanisole) diets in broilers and found no significant effect on the colour lightness, yellowness or brownness of the breast muscles. Among these three treatments, the $\mathrm{pH}$ values at $0,2.5$, and 5 hours post-slaughter were also not significantly affected, but rate of $\mathrm{pH}$ decline of breast muscles was $50 \%$ faster for broilers fed oxidized oil based diet between 0 and 1 hour post-slaughter than the control and antioxidant groups. The increased drip loss and decreased water holding capacity in the birds fed oxidized oil based diets was due to quicker drop of $\mathrm{pH}$ at early postmortem (0-1 hour) in the breast muscles. Birds fed with oxidized oil (PV: 156 meq $\mathrm{kg}^{-1}$ ) showed no pathological changes in the carcass and organs, i.e. muscular dystrophy during slaughter (Engberg et al., 1996). Zhang et al. (2011) documented 62.8\% higher drip loss in the breast muscle of broilers fed oxidized (PV: $100 \mathrm{meq} \mathrm{kg}^{-1}$ ) oil based diets compared with the control group (PV: 1 meq $\mathrm{kg}^{-1}$ ) after 1 day of storage at $4^{\circ} \mathrm{C}$. Cellular and subcellular membranes consist of a high amount of PUFAs and are susceptible to oxidation. The oxidation process leads to the production of free radicals that disrupt the membrane integrity resulting in more water leakage from the cells ultimately causing a greater drip loss (Mahan, 2001). 


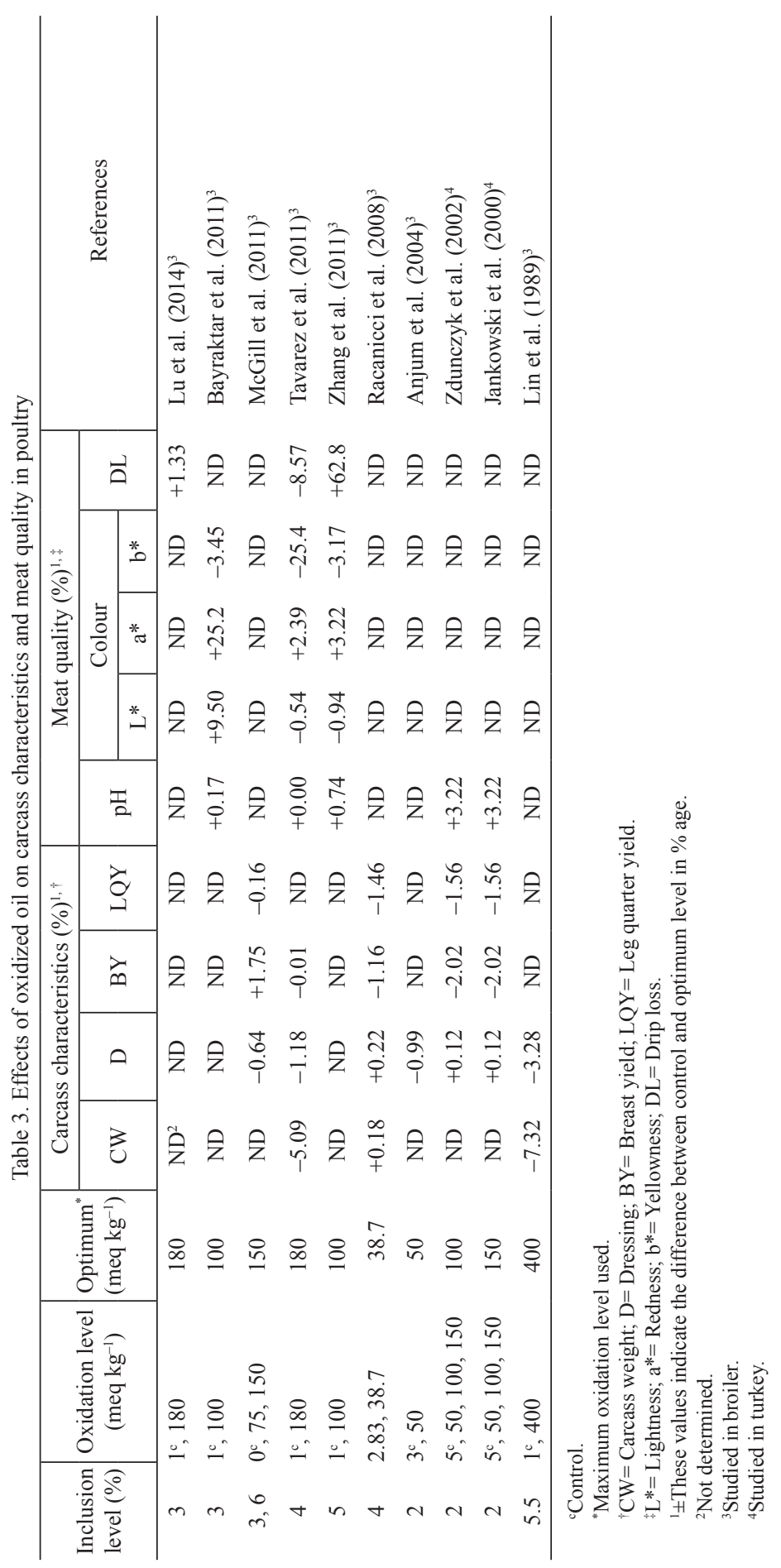




\section{Effects on blood chemistry and tissue oxidative status}

The influence of dietary oxidized oil on biochemical indices in the blood of poultry is presented in Table 4. Blood chemistry is a biochemical profile that is a reliable indicator of health and provides valuable information for evaluation of health status (Abdi-Hachesoo et al., 2011). Jankowski et al. (2000) evaluated the influence of fat (combination of rapeseed oil and poultry fat) with varied degrees of oxidation (PV: $<5$, 50,100 and $150 \mathrm{meq} \mathrm{kg}^{-1}$ ) on tocopherol as well as retinol concentrations in turkeys and reported that oxidized fat (PV: $150 \mathrm{meq} \mathrm{kg}^{-1}$ ) caused $29.7 \%$ reduction in tocopherol and $2.8 \%$ reduction in retinol concentration in serum compared to control group (PV: $<5$ meq $\mathrm{kg}^{-1}$ ). Engberg et al. (1996) studied the effects of oxidized vegetable oils (PV: $156 \mathrm{meq} \mathrm{kg}^{-1}$ ) with $11 \%$ inclusion level ( $9 \%$ rapeseed and $2 \%$ soybean oils) on tocopherol and retinol concentrations in broilers. The study reported a $6 \%$ lower concentration of $\alpha$-tocopherol in blood plasma of the birds compared with the fresh oil (PV: $1 \mathrm{meq} \mathrm{kg}^{-1}$ ), whereas the levels of $\gamma$-tocopherol and retinol in blood plasma were not affected. Tavarez et al. (2011) conducted an experiment to evaluate tocopherol level in serum of broilers fed oxidized oil (PV: 180 meq $\mathrm{kg}^{-1}$ ) based diets and found $58.5 \%$ lower tocopherol concentration compared to control group (PV: 1 meq $\mathrm{kg}^{-1}$ ).

Table 4. Biochemical indices in the blood of poultry fed oxidized oil

\begin{tabular}{|c|c|c|c|c|c|c|c|c|}
\hline \multirow{2}{*}{$\begin{array}{c}\text { Inclusion } \\
\text { level } \\
(\%)\end{array}$} & \multirow{2}{*}{$\begin{array}{c}\text { Oxidation } \\
\text { level } \\
\left(\mathrm{meq} \mathrm{kg}^{-1}\right)\end{array}$} & \multirow{2}{*}{$\begin{array}{l}\text { Optimum* } \\
\left(\mathrm{meq} \mathrm{kg}^{-1}\right)\end{array}$} & \multicolumn{5}{|c|}{ Biochemical indices $(\%)^{1}$} & \multirow[b]{2}{*}{ References } \\
\hline & & & $\begin{array}{c}\text { Vitamin } \\
\text { A }\end{array}$ & $\begin{array}{c}\text { Vitamin } \\
\mathrm{E}\end{array}$ & $\mathrm{TG}^{\dagger}$ & MDA & Cholesterol & \\
\hline 2 & $\begin{array}{l}7.5^{\mathrm{c}}, 50.5 \\
157,448.5\end{array}$ & 448.5 & $\mathrm{ND}^{2}$ & ND & ND & $+38.93^{p}$ & ND & Liang et al. $(2015)^{3}$ \\
\hline 3 & $1^{\mathrm{c}}, 100$ & 100 & ND & ND & $-49.23^{p}$ & $+53.84^{\mathrm{p}}$ & $-8.46^{p}$ & $\begin{array}{l}\text { Bayraktar et al. } \\
(2011)^{3}\end{array}$ \\
\hline 4 & $1^{\mathrm{c}}, 180$ & 180 & ND & $-58.47^{\mathrm{s}}$ & ND & ND & ND & Tavarez et al. $(2011)^{3}$ \\
\hline 4 & $\begin{array}{l}3.8^{\mathrm{c}}, 21.2 \\
56,88\end{array}$ & 88 & ND & ND & $-7.80^{\mathrm{s}}$ & ND & $-4.13^{\mathrm{s}}$ & Yue et al. $(2011)^{5}$ \\
\hline 6 & $1^{\mathrm{c}}, 148$ & 148 & ND & ND & $+5.26^{\mathrm{p}}$ & $+79.3^{p}$ & $+5.31^{\mathrm{p}}$ & Acikgoz et al. $(2011)^{3}$ \\
\hline 2 & $\begin{array}{l}5^{c}, 50,100, \\
150\end{array}$ & 150 & $-2.83^{\mathrm{s}}$ & $-29.76^{\mathrm{s}}$ & ND & ND & ND & $\begin{array}{l}\text { Zdunczyk et al. } \\
(2002)^{4}\end{array}$ \\
\hline 2 & $\begin{array}{l}5^{c}, 50,100, \\
150\end{array}$ & 150 & $-2.83^{\mathrm{s}}$ & $-29.71^{\mathrm{s}}$ & ND & ND & ND & $\begin{array}{l}\text { Jankowski et al. } \\
(2000)^{4}\end{array}$ \\
\hline 11 & $1^{\mathrm{c}}, 156$ & 156 & $-0.97^{p}$ & $-38.64^{p}$ & ND & ND & ND & Engberg et al. (1996) $)^{3}$ \\
\hline 8 & $1^{\mathrm{c}}, 55$ & 55 & ND & $-88.88^{p}$ & ND & ND & ND & Sheehy et al. $(1993)^{3}$ \\
\hline $\begin{array}{l}{ }^{ } \text {Contr } \\
{ }^{*} \text { Maxi } \\
{ }^{1} \pm \text { The } \\
{ }^{2} \text { Not d } \\
{ }^{\dagger} \text { Trigly } \\
{ }^{\dagger} \text { Malo } \\
{ }^{3} \text { Studi } \\
{ }^{4} \text { Studi } \\
{ }^{5} \text { Studi } \\
{ }^{\text {pPlasm }} \\
{ }^{5} \text { Serum }\end{array}$ & $\begin{array}{l}\text { rol. } \\
\text { imum oxidati } \\
\text { se values ind } \\
\text { determined. } \\
\text { yceride. } \\
\text { ondialdehyde. } \\
\text { ied in broiler. } \\
\text { ied in turkey. } \\
\text { ied in layer. } \\
\text { na. }\end{array}$ & licate the di & $\begin{array}{l}\text { d. } \\
\text { ference be }\end{array}$ & etween cc & ntrol and & optimum & evel in \% ag & \\
\hline
\end{tabular}


Bayraktar et al. (2011) studied the influence of oxidized oil (PV: $100 \mathrm{meq} \mathrm{kg} \mathrm{kg}^{-1}$ ) on triglyceride and cholesterol level in the blood plasma of broilers and reported that broilers fed oxidized oil (PV: 100 meq $\mathrm{kg}^{-1}$ ) had 49.2\% lower triglycerides and 8.4\% lower cholesterol in blood plasma compared to control group (PV: $1 \mathrm{meq} \mathrm{kg}^{-1}$ ). This decreased triglyceride concentration can be attributed to lower fatty acid de novo synthesis (Eder and Kirchgessner, 1999). Acikgoz et al. (2011) determined the influence of feeding oxidized oil (PV: 148 meq $\mathrm{kg}^{-1}$ ) on triglyceride and cholesterol concentration in blood plasma and found that oxidized dietary oil caused 5.3\% increase in the concentration of triglycerides and 5.3\% increase in cholesterol compared to control group (PV: 1 meq $\mathrm{kg}^{-1}$ ). Birds fed diets supplemented with oxidized oil (PV: 148 meq $\mathrm{kg}^{-1}$ ) and vitamin E (DL- $\alpha$-tocopherol acetate $200 \mathrm{mg} \mathrm{kg}^{-1}$ ) had $6.8 \%$ lower plasma triglycerides concentration and 5.9\% lower cholesterol concentration. Yue et al. (2011) performed an experiment to evaluate influence of oxidized oil with different PV (3.8, 21.2, 56.0, and 88.0 meq $\mathrm{kg}^{-1}$ ) on serum lipid concentrations in laying hens. These authors reported that oxidized oil (PV: 88 meq $\mathrm{kg}^{-1}$ ) caused $7.8 \%$ reduction in triglyceride and $4.1 \%$ reduction in total cholesterol level compared with the group fed fresh oil (PV: 3.8 meq $\mathrm{kg}^{-1}$ ). Juskiewicz et al. (2000) examined the influence of oxidized oil with varied degrees of oxidation (PV: 5, 40, 80, 120, 160, and $200 \mathrm{meq} \mathrm{kg}^{-1}$ ) in rats and found no significant effects on triglycerides and cholesterol concentration in the serum.

Malondialdehyde (MDA) is the main by-product of lipid oxidation and generally used to indicate the oxidative damage or stress. Weak antioxidant defence system and excessive production of free radicals causes oxidative stress that is a very harmful process (Kelly, 2003). The excess of free radicals can produce several harmful effects in the cells and tissues as well as the oxidation of lipids, proteins and DNA (Halliwell and Whiteman, 2004). Protein and DNA damage are assessed by quantifying the protein carbonyl concentration and 8-hydroxy 2-deoxyguanosine, respectively (Lindblom et al., 2019). Bayraktar et al. (2011) examined the influence of oxidized oil (PV: 100 meq $\mathrm{kg}^{-1}$ ) on MDA level in broilers and reported that there was 53.8\% higher MDA level in plasma compared with control group (PV: 1 meq kg-1), which showed an increased lipid peroxidation. Acikgoz et al. (2011) conducted a trial by offering $6 \%$ oxidized oil (PV: 148 meq $\mathrm{kg}^{-1}$ ) based diets to broilers to evaluate the MDA level and documented that oxidized oil caused $79.3 \%$ higher MDA in blood plasma compared to control group (PV: 1 meq kg-1). Liang et al. (2015) executed a study to examine the influence of oil with various oxidation levels (PV: 7.5, 50.5, 157, 247.5, 352.5, 448.5 meq kg-1) on MDA level of yellow male broilers fed corn-soy based diets and concluded that oxidized oil (PV: $448.5 \mathrm{meq} \mathrm{kg}^{-1}$ ) increased MDA level by $38.9 \%$ in blood plasma compared to control group (PV: 7.5 meq kg-1). Amount of thiobarbituric acid (TBA) is used to evaluate the quality of fat containing products. The products that have high TBA would not be suitable for use because it has high peroxide or aldehyde contents. Anjum et al. (2004) conducted a trial to evaluate the TBA in broiler meat and liver tissue by supplementing oxidized soybean oil (PV: 50 meq $\mathrm{kg}^{-1}$ ) in the diets and concluded that oxidized oil did not significantly affect the TBA number in broiler meat, whereas $23.3 \%$ higher TBA numbers in liver tissue were found compared to fresh oil based diets (PV: $3 \mathrm{meq} \mathrm{kg}^{-1}$ ). In the study by Tavarez et al. (2011), plasma TBA values of broilers receiving oxidized oil (PV: $180 \mathrm{meq} \mathrm{kg}^{-1}$ ) in diets were not significantly affected compared to control group receiving fresh $\left(\mathrm{PV}:<1\right.$ meq $\left.\mathrm{kg}^{-1}\right)$ soybean oil based diets. 
Tasaki and Okumura (1964) reported that uric acid in birds is the key end-product of nitrogen metabolism that plays a vital role as an antioxidant (Klandorf et al., 2001). Acikgoz et al. (2011) evaluated plasma uric acid concentration by supplementing oxidized oil in broiler diets and observed that thermally oxidized sunflower oil (PV: 148 meq $\mathrm{kg}^{-1}$ ) treated group had 2.1\% lower plasma uric acid concentration compared to control group (PV: 1 meq $\mathrm{kg}^{-1}$ ). These findings showed a milder oxidative stress in broilers fed oxidized sunflower oil based diets. Bayraktar et al. (2011) found that oxidized oil (PV: $100 \mathrm{meq} \mathrm{kg}^{-1}$ ) increased uric acid concentrations in plasma by $17.6 \%$ compared to control group (PV: 1 meq kg-1). Amount of uric acid was well associated with the concentrations of triglycerides and glucose. Plasma uric acid is needed as an antioxidant at a higher state of oxidation with increased concentrations of plasma glucose and triglyceride (Koga et al., 2004). In oxidative stress, nitric oxide activates the antioxidant enzymes (Dobashi et al., 1997) and plays a key part in the limitation of stress reactions, because of its antioxidant characteristics (Kanner et al., 1991). Acikgoz et al. (2011) concluded that oxidized oil supplementation (PV: $148 \mathrm{meq} \mathrm{kg}^{-1}$ ) did not influence the concentration of nitric oxide.

Glutathione peroxidase (GSH-Px) and total superoxide dismutase (T-SOD) are biomarkers of metabolic oxidative status. Tan et al. (2018 a) performed a study to estimate the influence of fish oil with different oxidation levels (PV: 20.8, 140.4, 183.6, 277.4 meq $\mathrm{kg}^{-1}$ ) on GSH-Px concentration in broilers and stated that GSH-Px concentration in the liver was not affected by oxidized oil based diets. Engberg et al. (1996) documented that GSH-Px concentration in liver of broilers remained unaffected by feeding diet containing oxidized vegetable oils (PV: $156 \mathrm{meq} \mathrm{kg}^{-1}$ ) at 11\% inclusion level ( $9 \%$ rapeseed and 2\% soybean oil), and reported that oxidized oil did not cause oxidative damage of liver. Bayraktar et al. (2011) examined the influence of oxidized oil (PV: 100 meq $\mathrm{kg}^{-1}$ ) on GSH-Px activity in blood plasma. This study found $27.2 \%$ higher GSH-Px concentration in broilers fed oxidized oil-based diets and documented that higher GSH-Px concentration can be an adaptive reaction to the increased oxidative stress and hydrogen peroxide production. Acikgoz et al. (2011) supplemented the male broilers diet with oxidized oil (PV: $148 \mathrm{meq} \mathrm{kg}{ }^{-1}$ ) and found that GSH-Px concentration in blood plasma remained unaffected. Tan et al. (2018 a) conducted an experiment to evaluate T-SOD concentration in the liver of broilers by supplementing oxidized oil with different oxidation levels of fish oil (PV: 20.8, 140.4, 183.6, 277.4 meq $\mathrm{kg}^{-1}$ ) and observed that dietary oxidized fish oil did not influence the T-SOD concentration in the liver of broilers at 14 or 21 day of age. The study also found no significant difference in T-SOD concentration of the jejunal and ileal mucosa. Liang et al. (2015) conducted a trial to examine the influence of oil with different PV $\left(7.5,50.5,157,248,353,449\right.$ meq $\left.\mathrm{kg}^{-1}\right)$ on T-SOD activity of yellow male broilers fed corn-soy based diets and reported that oxidized oil (PV: 449 meq $\mathrm{kg}^{-1}$ ) in broiler diets has no influence on T-SOD activity in blood, jejunal and ileal mucosa. Acikgoz et al. (2011) performed an experiment in broilers to examine T-SOD activity by supplementing oxidized oil (PV: $148 \mathrm{meq} \mathrm{kg}^{-1}$ ) in diet and observed that oxidized oil caused $46.6 \%$ reduction of T-SOD activity in blood plasma of male broilers. The reduction of T-SOD activity was because of its utilization against reactive oxygen species developed in erythrocytes. The influence of oxidized oil on antioxidant indices in the different tissues of poultry is shown in Table 5. 


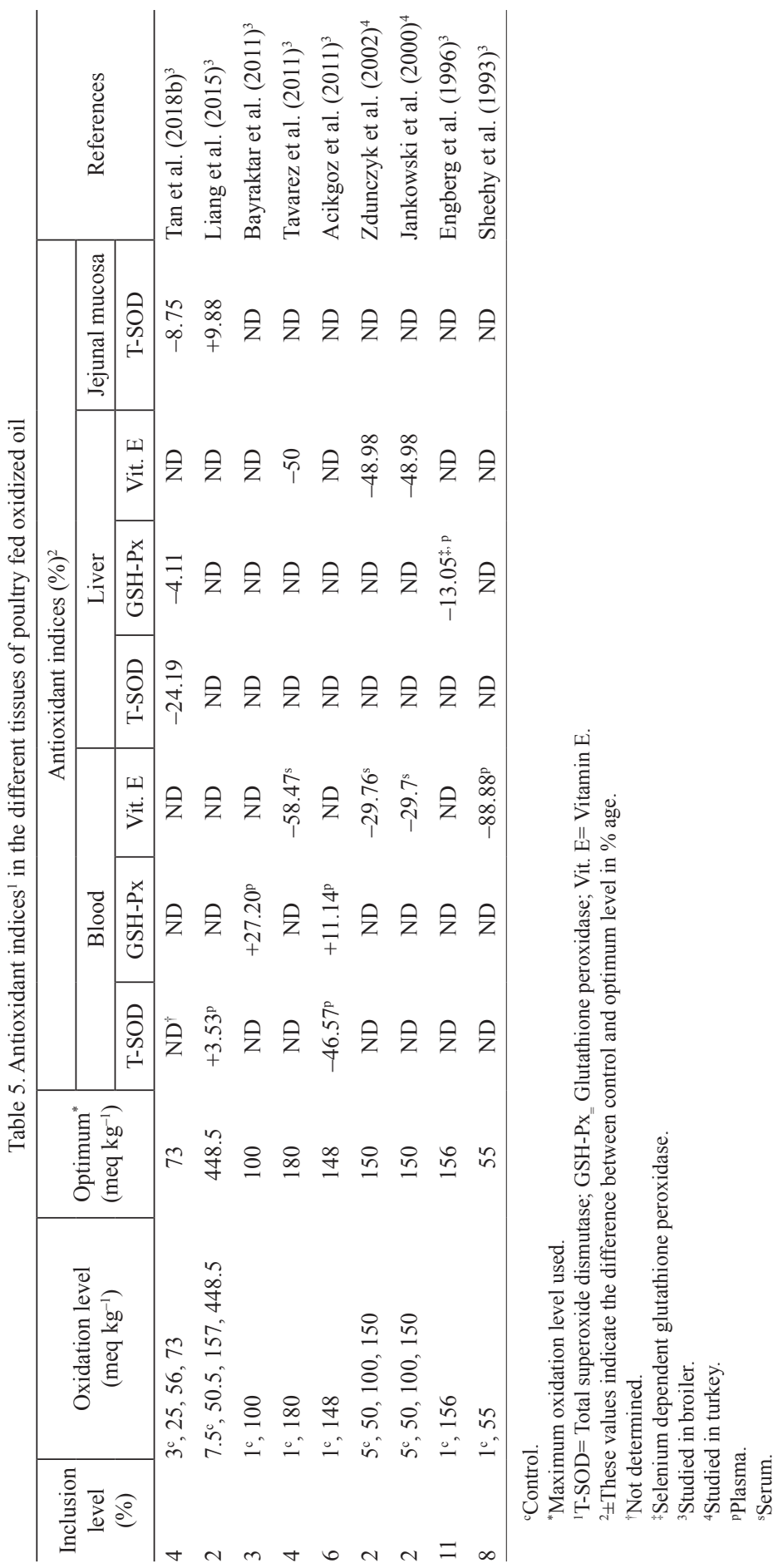




\section{Conclusions}

Mildly oxidized (PV: up to 20 meq $\mathrm{kg}^{-1}$ ) oil has negligible detrimental effects on growth performance, whereas moderately (PV: 20 to 50 meq $\mathrm{kg}^{-1}$ ) or highly oxidized (PV: 50 to 100 meq $\mathrm{kg}^{-1}$ or above) oil can cause depression in growth performance of broilers. This reduction in growth performance is caused by the oxidation products, which produce rancid odours and flavours resulting in a lower feed palatability and its intake, ultimately the growth performance. Oxidized oil with greater peroxide value (PV: $250 \mathrm{meq} \mathrm{kg}^{-1}$ ), additionally, reduces intestinal villus height that decreases the surface area available for nutrients absorption, resulting in a poor performance of the birds. The oxidation products lead to damage of fat soluble vitamins (A, D, $\mathrm{E}$ and $\mathrm{K}$ ) in blood resulting in an oxidative stress as indicated by greater MDA and GSH-Px values. The use of oxidized oil in poultry diets has no significant effect on dressing percentage, $\mathrm{pH}$ and meat colour, whereas carcass weight decreases and drip loss of meat increases. In conclusion, based on the results presented in the literature reviewed herein, the use of mildly oxidized (PV: 20 meq kg-1) oil in poultry feed at about 4 to $5 \%$ inclusion will decrease the feed cost and ultimately cost of poultry production. It can, therefore, replace fresh oil as an efficient, cost effective and sustainable energy source in poultry diets.

\section{References}

A bdi-Ha ches o o B., Ta l e bi A., A s ri - R e za e i S. (2011). Comparative study on blood profiles of indigenous and Ross-308 broiler breeders. Glob. Vet., 7: 238-241.

Acikgoz Z., Bayraktar H., Altan O., Akhisaroglu S.T., Kirkpinar F., Altun Z. (2011). The effects of moderately oxidized dietary oil with or without vitamin E supplementation on performance, nutrient digestibility, some blood traits, lipid peroxidation and antioxidant defence of male broilers. J. Sci. Food Agri., 91: 1277-1282.

A d e y e mi K.D., Shittu R.M., S abow A.B., Abubakar A.A., Karim R., Kar s ani S.A., S a zili A.Q. (2016). Comparison of myofibrillar protein degradation, antioxidant profile, fatty acids, metmyoglobin reducing activity, physicochemical properties and sensory attributes of gluteus medius and infraspinatus muscles in goats. J. Anim. Sci. Technol., 58: 1-17.

A $m$ a t C., P l a n a s J.M., M o r e to M. (1996). Kinetics of hexose uptake by the small and large intestine of the chicken. Am. J. Physiol. Regul. Integr. Comp. Physiol., 271: 1085-1089.

A n j u m M.I., M irza I.H., K h a n A.G., A z i m A. (2004). Effect of fresh versus oxidized soybean oil on growth performance, organs weights and meat quality of broiler chicks. Pak. Vet. J., 24: $173-178$.

B ayraktar H., A 1 tan O., A cikgoz Z., Baysal S.H., Seremet C. (2011). Effects of oxidized oil and vitamin $\mathrm{E}$ on performance and some blood traits of heat-stressed male broilers. S. Afr. J. Anim. Sci., 41: 288-296.

Belitz H.D., Grosch W., Schieberle P. (2009). Food Chemistry. Springer-Verlag. Berlin, pp. $158-247$.

B or st ing C.F., Eng b e rg R.M., J a k o b s e n K., J e n s e n S.K., A n d e r s e n J.O. (1994). Inclusion of oxidized fish oil in mink diets 1 . The influence on nutrient digestibility and fatty-acid accumulation in tissues. J. Anim. Physiol. Anim. Nutr., 72: 132-145.

B r a g a J.P., B a i a o N.C. (2001). Suplementaçao lipidica no desempenho de aves em altas temperaturas. Cadernos Tecnicos de Veterinaria e Zootecnia UFMG., 31: 23-28.

Cabel M.C., Wald roup P.W., Sher m e r W.D., C a l a b ot t a D.F. (1988). Effects of ethoxyquin feed preservative and peroxide level on broiler performance. Poultry Sci., 67: 1725-1730.

Clel and L.G., James M.J., Proudman S.M. (2005). Fish oil: what the prescriber needs to know. Arthritis Res. Ther., 8: 1-9. 
Da Rocha C., Maiorka A., De Paula Valle F.L., Gonsales Schramm V., Ange 1 i A.L., F i s c h e r D.S.A.V. (2012). The effect of soybean oil quality and vitamin E supplementation on turkey diet nutrition. J. Appl. Poult. Res., 21: 318-324.

D e 11 e s R.M., Xi ong Y.L., True A.D., A o T., D a w s o n K.A. (2015). Augmentation of waterholding and textural properties of breast meat from oxidatively stressed broilers by dietary antioxidant regimens. Br. Poult. Sci., 56: 304-314.

Dibner J.J., Richards J.D. (2004). The digestive system: challenges and opportunities. J. Appl. Poult. Res., 13: 86-93.

D i b n e r J.J., A t w e 11 C.A., K i t c h e 11 M.L., S h e r m e r W.D., I v e y F.J. (1996). Feeding of oxidized fats to broilers and swine: effects on enterocyte turnover, hepatocyte proliferation and the gut associated lymphoid tissue. Anim. Feed Sci. Technol., 62: 1-13.

Dobashi K., Pahan K., Chahal A., Singh I. (1997). Modulation of endogenous antioxidant enzymes by nitric oxide in rat C6 glial cells. J. Neurochem., 68: 1896-1903.

E d e r K., K ir ch ges s n e r M. (1999). The effect of a moderately thermoxidized dietary fat on the vitamin E status, the fatty acid composition of tissue lipids, and the susceptibility of low-density lipoproteins to lipid peroxidation in rats. Lipid/Fett., 101: 178-184.

Eder K., Skufca P., Brandsch C. (2002). Thermally oxidized dietary fats increase plasma thyroxine concentrations in rats irrespective of the vitamin E and selenium supply. J. Nutr., 132: 1275-1281.

Eder K., K ell e r U., Hir che F., B rand s c h C. (2003). Thermally oxidized dietary fats increase the susceptibility of rat LDL to lipid peroxidation but not their uptake by macrophages. J. Nutr., 133: 2830-2837.

E h r I.J., K e r r B.J., P e r s i a M.E. (2015). Effects of peroxidized corn oil on performance, AMEn, and abdominal fat pad weight in broiler chicks. Poultry Sci., 94: 1629-1634.

Engberg R.M., Lauridsen C., Jens en S.K., Jakobsen K. (1996). Inclusion of oxidized vegetable oil in broiler diets. Its influence on nutrient balance and on the antioxidative status of broilers. Poultry Sci., 75: 1003-1011.

F r a n k e l E.N. (1991). Recent advances in lipid oxidation. J. Sci. Food Agric., 54: 495-511.

G o u s R.M., M or r is T.R. (2005). Nutritional interventions in alleviating the effects of high temperature in broilers production. World Poultry Sci. J., 61: 463-475.

$\mathrm{H}$ a $11 \mathrm{iw}$ e 11 B., Wh it e m a n M. (2004). Measuring reactive species and oxidative damage in vivo and in cell culture: how should you do it and what do the results mean? Br. J. Pharmacol., 142: 231-255.

J a k o bs e n C. (1999). Sensory impact of lipid oxidation in complex food system. Lipid/ Fett., 101: 484-492.

Jankowski J., Zdunczyk Z., Koncicki A., Juskiewicz J., Faruga A. (2000). The response of turkeys to diets containing oxidized fat of differing degree of oxidation. J. Anim. Feed Sci., 9: 363-370.

J en s e n C., En g b erg R., J a k o b s e n K., S k ib st ed L.H., B e r te ls e n G. (1997). Influence of the oxidative quality of dietary oil on broiler meat storage stability. Meat Sci., 47: 211-222.

Junque ir a O.M., Andre ot t i M.D.O., Araujo L.F., Duarte K.F., Can che rin i L.C., Ro drigues E.A. (2005). Valor energetico de algumas fontes lipídicas determinado com frangos de corte. R. Bras. Zootech., 34: 2335-2339.

Juskiewicz J., Dlugoszewska M., Zdunczyk Z., Krasnodebska-Depta A., K refft B., S a d ow s k a J. (2000). The response of rats to long-term feeding with diets containing oxidized fat. 2. Biochemical indicator in the serum, liver, and bone mineralization. J. Anim. Feed Sci., 9: 149-157.

K a n ner J., H a r e 1 S., R in a G. (1991). Nitric oxide as an antioxidant. Arch. Biochem. Biophys., 289: $130-136$.

K eller U., Brands ch C., Eder K. (2004). The effect of dietary oxidized fats on the antioxidant status of erythrocytes and their susceptibility to haemolysis in rats and guinea pigs. J. Anim. Physiol. Anim. Nutr., 88: 59-72.

K e 11 y F.J. (2003). Oxidative stress: its role in air pollution and adverse health effects. J. Occup. Environ. Med., 60: 612-616.

K e r r B.J., Ke 11 n e r T.A., S hurs on G.C. (2015). Characteristics of lipids and their feeding value in swine diets. J. Anim. Sci. Biotechnol., 6: 1-30. 
Ketels E., De Groote G. (1988). The nutritional value for broilers of fats characterized by short-chain fatty acids as affected by level of inclusion and age. Anim. Feed Sci. Technol., 22: 1 05-118.

K i m u ra T., I i d a K., Tak e i Y. (1984). Mechanisms of adverse effect of air-oxidized soybean oilfeeding in rats. J. Nutr. Sci. Vitaminol., 30: 125-133.

K landorf H., Rathore D.S., Iqbal M., Shi X., van Dyke K. (2001). Accelerated tissue aging and increased oxidative stress in broiler chickens fed allopurinol. Comp. Biochem. Physiol. C. Toxicol. Pharmacol., 129: 93-104.

K o g a Y., S a i t o S., K a n e k o K., K i d o Y., F u ru s e M. (2004). Changes in plasma constituents of crossbred (Aigamo) ducks during the winter season. Poultry Sci., 41: 131-139.

Liang F., Jiang S., Mo Y., Zhou G., Yang L. (2015). Consumption of oxidized soybean oil increased intestinal oxidative stress and affected intestinal immune variables in yellow-feathered broilers. Asian-Australas. J. Anim. Sci., 28: 1194-1201.

L i ma D.M., Rangel A., Urbano S., Mitzi G., Moreno G.M. (2013). Oxidacao lipidica da carne ovina. Acta. Vet. Bras., 7: 14-28.

L in C.F., A s g ha r A., G r a y J.I., B u c k le y D.J., B o or en A.M., C r a c k el R.L., F le ga 1 C.J. (1989). Effects of oxidized dietary oil and antioxidant supplementation on broiler growth and meat stability. Br. Poult. Sci., 30: 855-864.

L in d b lo m S.C., G a ble r N.K., B o b e ck E.A., K e r r B.J. (2019). Oil source and peroxidation status interactively affect growth performance and oxidative status in broilers from 4 to $25 \mathrm{~d}$ of age. Poultry Sci., 98: 1749-1761.

L u T., Harper A.F., Z h a o J., D a 11 oul R.A. (2014). Effects of a dietary antioxidant blend and vitamin $\mathrm{E}$ on growth performance, oxidative status, and meat quality in broiler chickens fed a diet high in oxidants. Poultry Sci., 93: 1649-1657.

Mah a D.C. (2001). Selenium and Vitamin E in Swine Nutrition. Swine Nutrition. Washington, DC, CRC Press, 2nd ed., pp. 281-310.

McGil1 J., McGil1 E., Kam yab A., Firman J. (2011). Effect of high peroxide value fats on performance of broilers in a normal immune state. Int. J. Poult. Sci., 10: 241-246.

Mos s a b A., Hallou is J.M., Le s s ire M. (2000). Utilization of soybean oil and tallow in young turkeys compared with young chickens. Poultry Sci., 79: 1326-1331.

Orsavova J., Misurcova L., Ambrozova V.J., Vicha R., Mlcek J. (2015). Fatty acids composition of vegetable oils and its contribution to dietary energy intake and dependence of cardiovascular mortality on dietary intake of fatty acids. Int. J. Mol. Sci., 16: 12871-12890.

Racanic i A.M.C., Menten J.F.M., Regitano-D'Arce M.A.B., Torres E.A.F.D. S., P in o L.M., P e dro s o A.A. (2008). Dietary oxidized poultry offal fat: broiler performance and oxidative stability of thigh meat during chilled storage. Braz. J. Poult. Sci., 10: 29-35.

Sabow A.B., Zulkifli I., Goh Y.M., Ab Kadir M.Z.A., Kaka U., Imlan J.C., Sazi 1 i A.Q. (2016). Bleeding efficiency, microbiological quality and oxidative stability of meat from goats subjected to slaughter without stunning in comparison with different methods of pre-slaughter electrical stunning. PLoS One, 11: 1-18.

Sheehy P.J.A., Morriss ey P.A., Flynn A. (1993). Influence of heated vegetable oils and $\alpha$-tocopheryl acetate supplementation on $\alpha$-tocopherol, fatty acids and lipid peroxidation in chicken muscle. Br. Poult. Sci., 34: 367-381.

Shurs on G.C., Kerr B.J., Han s on A.R. (2015). Evaluating the quality of feed fats and oils and their effects on pig growth performance. J. Anim. Sci. Biotechnol., 6: 1-10.

Tan L., R ong D., Yang Y., Zhang B. (2018 a). The effect of oxidized fish oils on growth performance, oxidative status, and intestinal barrier function in broiler chickens. J. Appl. Poult. Res., 28: $31-41$.

Tan L., R ong D., Yang Y., Z h ang B. (2018 b). Effect of oxidized soybean oils on oxidative status and intestinal barrier function in broiler chickens. Braz. J. Poult. Sci., 20: 333-342.

Tasaki I., Okumura J. (1964). Effect of protein level of diet on nitrogen excretion in fowls. J. Nutr., 83: 34-38.

Tavarez M.A., B oler D.D., B ess K.N., Zhao J., Yan F., Dilger A.C., Mcke ith F.K., Kille fer J. (2011). Effect of antioxidant inclusion and oil quality on broiler performance, meat quality, and lipid oxidation. Poultry Sci., 90: 922-930. 
Tres A., B ou R., Guardiola F., Nuchi C.D., Magrinya N., Codony R. (2013). Use of recovered frying oils in chicken and rabbit feeds: effect on the fatty acid and tocol composition and on the oxidation levels of meat, liver and plasma. Animal, 7: 505-517.

Varady J., Ges sner D.K., Most E., Ed e r K., R ing s e is R. (2012). Dietary moderately oxidized oil activates the Nrf2 signaling pathway in the liver of pigs. Lipids Health Dis., 11: 1-9.

Wang L., Zh ang J., G a o J., Q i a n Y., L ing Y. (2016). The effect of fish oil-based lipid emulsion and soybean oil-based lipid emulsion on cholestasis associated with long-term parenteral nutrition in premature infants. Gastroent. Res. Pract., 2016: 1-4.

W i s e $\mathrm{m}$ a n J. (1999). Optimizing the role of fats in diet formulation. In: Proceedings of the Australian Poultry Science Symposium, pp. 8-15.

Ya m a u chi K.E., I s s h i k i Y. (1991). Scanning electron microscopic observations on the intestinal villi in growing White Leghorn and broiler chickens from 1 to 30 days of age. Br. Poult. Sci., 32: $67-78$

Y in H., X u L., P o r t e r N.A. (2011). Free radical lipid peroxidation: mechanisms and analysis. Chem. Rev., 111: 5944-5972.

Yu e H.Y., Wang J., Q i X.L., J i F., Li u M.F., Wu S.G., Zhang H.J., Qi G.H. (2011). Effects of dietary oxidized oil on laying performance, lipid metabolism, and apolipoprotein gene expression in laying hens. Poultry Sci., 90: 1728-1736.

Zdunczyk Z., Jusk i ew i c z J., D lug os zew ska M., Frejnagel S., Koncicki A. (2000). The response of rats to long-term feeding with diets containing oxidized fat. 1. Thermooxidative changes in fat, body weight gain, feed consumption and utilisation. J. Anim. Feed Sci., 9: 137-146.

Zdunczyk Z., Jankowski J., Koncicki A. (2002). Growth performance and physiological state of turkeys fed diets with higher content of lipid oxidation products, selenium, vitamin $\mathrm{E}$ and vitamin A. World Poultry Sci. J., 58: 357-364.

Zhang W., Xi a o S., L e e E.J., A h n D.U. (2011). Consumption of oxidized oil increases oxidative stress in broilers and affects the quality of breast meat. J. Agric. Food Chem., 59: 969-974.

Received: 12 XI 2019

Accepted: 27 III 2020 